\title{
TERMINOLOGIA PARA AS TÉCNICAS ANALÍTICAS DE ELETROMIGRAÇÃo EM CAPILARES ${ }^{*}$
}

\author{
José Alberto Fracassi da Silva* \\ Instituto de Química, Universidade Estadual de Campinas, CP 6154, 13083-970 Campinas - SP, Brasil \\ Wendell Karlos Tomazelli Coltro e Emanuel Carrilho \\ Instituto de Química de São Carlos, Universidade de São Paulo, CP 780, 13560-970 São Carlos - SP, Brasil \\ Marina Franco Maggi Tavares \\ Instituto de Química, Universidade de São Paulo, CP 26077, 05513-970 São Paulo - SP, Brasil
}

Recebido em 4/7/06; publicado na web em 19/1/07

\begin{abstract}
This is a contribution that presents a translation of the work "Terminology for Analytical Capillary Electromigration Techniques" by Riekkola and collaborators (Pure Appl. Chem., Vol. 76, No. 2, 443-451, 2004) from IUPAC ${ }^{\odot}$ for the Portuguese Language. Additional terms that had not been defined in native Portuguese were included for the benefit of the local community. Additional notes were also included to clarify some important concepts and to highlight the differences between techniques.
\end{abstract}

\section{INTRODUÇÃO}

Técnicas que empregam eletromigração em capilares têm se tornado populares e crescido em importância na química analítica, especialmente no campo da bioanálise. Parte dos termos empregados pode ser encontrada em um artigo sobre a terminologia de eletroforese em química clínica ${ }^{1}$, mas em muitos casos estes não podem ser aplicados a técnicas capilares e não levam completamente em conta as definições sugeridas pela IUPAC ${ }^{2}$. Em 1994, Knox publicou um artigo sobre a terminologia a ser empregada em técnicas de eletrosseparação ${ }^{3}$, embora este não esteja em concordância com a nomenclatura da IUPAC para cromatografia ${ }^{4}$. O presente artigo discute e define os termos relevantes utilizados na prática laboratorial, incluindo os nomes das várias técnicas baseadas nos princípios da eletromigração. Deve ser notado que diversas aplicações práticas podem se situar em casos limites, no que diz respeito ao nome de uma destas técnicas em particular.

As separações efetuadas com técnicas de eletromigração em capilar utilizam capilares de diâmetro interno reduzido e empregam campos elétricos elevados, sendo baseadas em diferentes princípios de separação que, em alguns casos, podem se sobrepor. Estas incluem as técnicas eletroforéticas capilares e as técnicas cromatográficas capilares que utilizam campo elétrico para bombeamento dos fluidos. Técnicas de eletromigração em capilares têm se mostrado altamente eficientes na separação de íons pequenos, tanto orgânicos como inorgânicos, fármacos, explosivos, corantes, polímeros, proteínas e peptídeos, DNA e RNA, células, partículas, etc. ${ }^{5-10}$.

A presença do fluxo eletrosmótico (EOF, "electroosmotic flow") pode contribuir para a separação, mesmo quando não é necessária (por ex., em focalização isoelétrica), ou pode ser completamente indesejável. O EOF tem sua origem na atuação de um campo elétrico sobre as espécies carregadas na região difusa da dupla camada elétrica, formada devido à carga da parede interna do capilar. Como exemplo, para um capilar de sílica fundida em contato com uma

\#Artigo traduzido de "Terminology for analytical capillary electromigration techniques", publicado em Pure Appl. Chem. 2004, 76, 443, por M. L. Riekkola, J. A. Jönsson e R. M. Smith. Publicação aprovada pelo Comitê Brasileiro para Assuntos de Química junto à IUPAC.

"e-mail: fracassi@iqm.unicamp.br solução com valor de $\mathrm{pH}$ acima de 2, os grupos silanol da superfície apresentam-se desprotonados e proporcionam carga negativa à parede. Para contrabalancear as cargas da parede há, na região próxima à parede, o excesso de cargas positivas, provenientes dos cátions da solução. A aplicação do campo elétrico ao longo do capilar causa a movimentação dos íons positivamente carregados, presentes na camada difusa, no sentido do cátodo. Para distâncias maiores que a definida pelo plano de cisalhamento, no qual a velocidade eletrosmótica é zero, encontra-se que esta velocidade aumenta rapidamente, até que para distâncias maiores que a espessura da camada difusa (comprimento de Debye) assume um valor constante. Para experimentos de eletromigração em capilares, a espessura da camada difusa é muito menor que o raio do capilar, de modo que o perfil de velocidade radial aparece como linear. Como conseqüência, o EOF permite altas eficiências nas separações, em comparação às técnicas que empregam pressão para bombeamento dos fluidos, cujo perfil de velocidade radial é parabólico.

Algumas das vantagens destas técnicas de eletromigração incluem eficiências de separação extremamente altas, tempo de análise relativamente curto, pequenas quantidades de amostra e baixo custo de análise. Além disso, instrumentos comerciais automatizados permitem operação confiável em análises de rotina.

Tipicamente são utilizados capilares com diâmetro interno de 20-100 $\mu \mathrm{m}$ e comprimento de 20-100 cm. Na separação de moléculas pequenas, capilares de sílica fundida sem recobrimento da superfície interna são comumente empregados. Para prevenir a adsorção de analitos ou componentes da matriz e para eliminar ou controlar o EOF, o recobrimento ou a modificação química dos grupos silanol presentes na superfície pode ser necessária. Recobrimentos neutros e carregados têm sido usados com sucesso em grande variedade de aplicações.

A injeção da amostra no capilar pode ser feita hidrodinamicamente, através da criação de um gradiente de pressão entre os reservatórios da amostra e do eletrólito de corrida, enquanto as extremidades do capilar estão mergulhadas nestes reservatórios. Utilizando a injeção eletrocinética, um determinado valor de potencial é aplicado entre os reservatórios da amostra e eletrólito durante um intervalo de tempo definido, enquanto a extremidade apropriada do capilar é inserida no reservatório da amostra, ao passo que a outra extremidade é colocada no reservatório do eletrólito de corrida. 
Idealmente, efeitos de dispersão da zona durante a separação são devidos apenas à difusão longitudinal. Entretanto, eletrodispersão (causada pelas diferenças de condutividade entre as zonas do eletrólito e da amostra), bem como os gradientes de temperatura no interior do capilar podem causar efeitos adicionais de alargamento das bandas. O tipo de técnica de introdução de amostra, volume injetado em excesso, tipo de matriz e fenômeno de adsorção na parede do capilar podem vir a ser fontes adicionais de alargamento das bandas. $\mathrm{O}$ controle da temperatura do capilar de separação, a escolha apropriada do tampão de corrida, as técnicas de tratamento da superfície do capilar, o tipo de amostra e o modo como é injetada podem ser cruciais para o sucesso de uma separação particular.

Aditivos, como solventes orgânicos, ciclodextrinas ou polímeros, podem ser usados para controlar a migração e o formato dos picos dos solutos. Ciclodextrinas podem também ser utilizadas como parte do recobrimento da parede do capilar, em géis rígidos e em fases dispersas micelares. Capilares preenchidos com géis contendo ligações cruzadas, como por ex. a poliacrilamida, podem ser utilizados como meio na separação baseada no tamanho de biomoléculas de alta massa molar. A incorporação de diferentes seletores quirais ao tampão ou eletrólito de corrida tem sido utilizada com sucesso na separação de compostos quirais de baixa massa molar. Polímeros lineares emaranhados são freqüentemente utilizados na separação de biomoléculas.

Em eletrocromatografia capilar ${ }^{11,12}$, as separações são efetuadas em colunas capilares contendo recheio particulado, como em cromatografia líquida de alta eficiência, ou material monolítico. Capilares sem recheio e contendo apenas a parede recoberta, como os capilares utilizados em cromatografia gasosa capilar, também têm sido empregados.

No futuro, microcanais contidos em estruturas baseadas em microdispositivos tenderão a ser utilizados com maior frequiência em técnicas de eletromigração capilar, após maiores desenvolvimentos no campo da nanotecnologia.

Há disponível em Língua Portuguesa alguns artigos de revisão que envolvem fundamentos das técnicas eletroforéticas de separação ${ }^{13-16}$ e aspectos relacionados ${ }^{17-19}$.

\section{TÉCNICAS DE ELETROMIGRAÇÃO EM CAPILARES}

Eletroforese Capilar (CE, “capillary electrophoresis")

É a técnica de separação efetuada em capilares e baseada somente nas diferenças entre as mobilidades de espécies carregadas (analitos), em eletrólitos que podem ser aquosos ou orgânicos. Estes podem conter aditivos, como ciclodextrinas, complexantes ou ligantes, que interagem com os analitos e alteram suas mobilidades eletroforéticas.

Notas: 1. Esta técnica também é conhecida por eletroforese capilar de zona (CZE, "capillary zone electrophoresis") ou em solução livre (FSCE, "free solution capillary electrophoresis"). 2. O uso do termo eletroforese capilar (CE) como um termo coletivo para todas as técnicas de eletromigração não é recomendado, pois muitas destas técnicas envolvem outros mecanismos de separação que não o descrito acima. 3. Alguns autores têm se referido à utilização de ciclodextrinas carregadas no eletrólito como cromatografia eletrocinética.

\section{Eletroforese Capilar de Afinidade (CAE, “capillary affinity electrophoresis")}

É uma técnica eletroforética de separação em capilares na qual substâncias capazes de interagir especificamente (muitas vezes bio-especifica- mente) com os analitos são adicionadas ao eletrólito de corrida.

Nota: A mesma técnica é conhecida por ACE ("affinity capillary electrophoresis").

\section{Eletroforese Capilar de Peneiramento (CSE, “capillary sieving electrophoresis")}

Técnica de separação eletroforética em capilar contendo um meio peneirador (por ex., rede de polímeros lineares emaranhados) no eletrólito de corrida. A separação é baseada nas diferenças de forma e tamanho entre os analitos carregados.

\section{Eletroforese Capilar em Gel (CGE, "capillary gel electrophoresis")}

Caso especial de eletroforese capilar de peneiramento, no qual o capilar é preenchido com gel contendo ligações cruzadas.

\section{Focalização Isoelétrica Capilar (CIEF, "capillary isoelectric focusing”)}

Técnica eletroforética para separação de analitos anfóteros de acordo com seu ponto isoelétrico, através da aplicação de um campo elétrico ao longo de um gradiente de $\mathrm{pH}$ gerado no capilar.

\section{Isotacoforese Capilar (CITP, “capillary isotachophoresis")}

Técnica de separação eletroforética efetuada em um sistema descontínuo de eletrólitos, no qual os analitos migram de acordo com suas mobilidades eletroforéticas, formando uma cadeia de zonas adjacentes que se movem com igual velocidade entre duas soluções, os eletrólitos líder e terminador. As condições que devem ser satisfeitas para que os analitos migrem em zonas adjacentes são que as mobilidades dos íons do eletrólito líder e terminador sejam maior e menor, respectivamente, que as mobilidades dos íons na amostra.

\section{Cromatografia Eletrocinética (EKC, "electrokinetic chromatography")}

Técnica de separação baseada na combinação de eletroforese e interações dos analitos com aditivos (por ex., tensoativos), de modo a formar uma fase dispersa que se mova com velocidade diferente do analito. De maneira a promover a separação, os analitos ou a fase dispersa devem possuir carga.

Notas: 1. Esta definição não é totalmente compatível com a definição de cromatografia. 2. A mesma técnica é também conhecida por cromatografia capilar eletrocinética (ECC, "electrokinetic capillary chromatography").

\section{Cromatografia Eletrocinética Micelar (MEKC, "micellar electrokinetic chromatography")}

Caso especial da cromatografia eletrocinética, em que a fase dispersa no capilar é micelar.

Nota: A mesma técnica é conhecida por cromatografia capilar eletrocinética micelar (MECC, "micellar electrokinetic capillary chromatography").

\section{Cromatografia Eletrocinética em Microemulsão (MEEKC, "microemulsion electrokinetic chromatography")}

Caso especial da cromatografia eletrocinética, no qual uma microemulsão é empregada como fase dispersa. 
Nota: A mesma técnica é também chamada de cromatografia capilar eletrocinética em microemulsão (MEECC, "microemulsion electrokinetic capillary chromatography").

\section{Eletrocromatografia Capilar (CEC, "capillary electrochromatography")}

Caso especial da cromatografia líquida capilar, no qual a movimentação da fase móvel através de um capilar preenchido ou recoberto com a fase estacionária é promovida pelo fluxo eletrosmótico (que pode ser assistido por pressão). O tempo de retenção é determinado pela combinação da migração eletroforética e da retenção cromatográfica.

\section{TERMOS RELACIONADOS ÀS TÉCNICAS DE ELETROMIGRAÇÃO EM CAPILARES}

\section{Eletrosmose}

É o movimento de um líquido através de uma membrana (ou capilar) como consequiência da aplicação de um campo elétrico.

Nota: A velocidade linear do fluxo dividida pelo campo elétrico aplicado é chamada de mobilidade eletrosmótica $\left(u\right.$ ou $\left.\mu_{\mathrm{eo}}\right)$.

\section{Fluxo Eletrosmótico em Volume}

É o fluxo em volume dividido pelo campo elétrico aplicado sobre o plug total ou capilar. Corrigido da ref. 2.

\section{Tempo de Migração Eletrosmótico, $t_{\text {eo }}$}

É o tempo requerido para que o líquido percorra o comprimento efetivo do capilar, $\mathrm{L}_{\mathrm{ef}}$, devido à eletrosmose. Este tempo é comumente medido como o tempo de "migração" de um marcador neutro, conhecido como marcador do fluxo eletrosmótico e cuja mobilidade é assumida desprezível com relação ao analito.

\section{Velocidade Eletrosmótica, $v_{\text {eo }}$}

Veja eletrosmose ${ }^{2}$.

Nota: Em técnicas de eletromigração capilar, esta velocidade é positiva, por convenção, no sentido da extremidade de injeção de amostra para a extremidade de detecção do capilar, caso contrário ela assume valor negativo. A velocidade eletrosmótica pode ser calculada como $v_{\mathrm{eo}}=\mathrm{L}_{\mathrm{ef}} / \mathrm{t}_{\mathrm{eo}}$, o comprimento efetivo do capilar dividido pelo tempo de migração eletrosmótico.

\section{Campo Elétrico, $E$}

É a força que atua sobre uma partícula carregada dividida pela sua carga elétrica.

Nota: Em técnicas de eletromigração capilar, esta é tomada como a componente axial do campo, que é a diferença de potencial aplicada nas extremidades do capilar dividida pelo comprimento total do capilar, $\mathrm{L}_{\text {tot }}$. Existe também um campo elétrico radial proveniente da dupla camada elétrica formada nas proximidades da parede do capilar, que está envolvida no fenômeno da eletrosmose. O comprimento total do capilar é tipicamente maior que o comprimento efetivo, $\mathrm{L}_{\mathrm{ef}}$. Veja também tempo de migração.

\section{Mobilidade Eletrosmótica, $u$ ou $\mu_{\mathrm{eo}}$}

Velocidade eletrosmótica dividida pelo campo elétrico.

$$
\mu_{e o}=\frac{v_{e o}}{E}
$$

\section{Potencial Eletrocinético, $\zeta$}

É o potencial no plano de cisalhamento que se encontra na camada difusa e está associado ao fenômeno da eletrosmose. $\zeta$ é negativo quando os vetores de campo elétrico $(E)$ e velocidade do fluxo $\left(v_{\text {eo }}\right)$ estão na mesma direção e sentido. No cálculo do potencial eletrocinético a partir dos fenômenos eletrocinéticos, assume-se que o plano de cisalhamento divide a camada difusa em duas regiões distintas: uma imóvel e outra móvel. Como não estão disponíveis dados confiáveis a respeito da permitividade e viscosidade na região da dupla camada elétrica próxima à interface, o cálculo do potencial eletrocinético está sujeito a críticas. Torna-se, portanto, essencial indicar em todos os casos quais equações foram utilizadas para cálculo do $\zeta$. Entretanto, para as mesmas suposições sobre permitividade e viscosidade, todos os fenômenos eletrocinéticos devem fornecer o mesmo valor para o potencial eletrocinético ${ }^{2}$.

Notas: 1. Se as condições referidas acima forem seguidas, o potencial eletrocinético pode ser relacionado à mobilidade do fluxo eletrosmótico, $\mu_{\mathrm{eo}}$, pela Equação de Smoluchowski:

$\mu_{e o}=-\frac{\varepsilon_{r} \varepsilon_{0} \zeta}{\eta}$

onde $\varepsilon_{\mathrm{r}}$ é a permitividade da solução (usualmente tomada como a permitividade do solvente puro), $\varepsilon_{0}$ é a permitividade do vácuo e $\eta$ é a viscosidade dinâmica da solução, na qual se assume que a razão entre a permitividade e a viscosidade é independente do campo elétrico na dupla camada elétrica. 2 . O potencial eletrocinético é também conhecido por potencial zeta.

\section{Tempo de Migração, $t_{\mathrm{m}}$}

É o tempo requerido para que o analito percorra o caminho efetivo do capilar, $\mathrm{L}_{\mathrm{ef}}$, que é a distância entre os pontos de injeção e detecção.

\section{Taxa de Migração (em eletroforese), $v$}

É a distância de migração dividida pelo tempo, às vezes chamada de velocidade de migração. O símbolo $v$ também é usado para velocidade ${ }^{2}$.

\section{Velocidade Eletroforética, $\boldsymbol{v}_{e p}$}

É a velocidade que um analito carregado adquire sob ação de um campo elétrico, em relação ao eletrólito de corrida. Também chamada de taxa de migração (em eletroforese).

\section{Mobilidade Eletroforética, $\mu$ ou $\mu_{\text {ep }}$}

É a taxa de migração observada (em eletroforese), v, ou a velocidade eletroforética, $v_{\text {ep }}$, dividida pela magnitude do campo elétrico aplicado, E, em um dado meio.

Notas: 1. Mobilidades podem ser expressas com sinal negativo, pois a migração de solutos ou partículas pode ocorrer no sentido contrário àquele do campo elétrico (que é tomado como referência). 2. Em um meio de suporte sólido, apenas valores aparentes podem ser determinados. (Modificado da ref. 2). 3. A mobilidade eletroforética de um íon é dada por: 
$\mu_{e p}=\frac{z e}{f}$

Nesta equação, $f$ é o coeficiente de atrito, $z$ é o número de cargas elementares do íon e $e$ é a carga elementar. O coeficiente de atrito aumenta com o tamanho do íon e com a viscosidade do eletrólito suporte. Para íons esféricos rígidos, de raio $r$, movendose em um meio de viscosidade $\eta$, o coeficiente de atrito pode ser estimado utilizando-se a Lei de Stokes:

$f=6 \pi \eta r$

Coeficientes de atrito para partículas de outros formatos, como elipsóides, podem ser estimados utilizando-se equações mais complexas.

\section{Mobilidade Eletroforética Efetiva, $\mu_{\mathrm{ef}}$}

A mobilidade eletroforética efetiva de um analito é dada pela somatória das mobilidades eletroforéticas $\left(\mu_{i}\right)$ de todas as $n$ espécies relacionadas entre si por equilíbrios químicos, multiplicadas pela distribuição destas espécies $\left(\alpha_{j}\right)$ :

$\mu_{e f}=\sum_{j=1}^{n} \alpha_{j} \mu_{j}$

Velocidade Total do Analito (em eletroforese capilar), $v_{\text {tot }}$

É a soma da velocidade eletroforética, $v_{\mathrm{ep}}$, com a velocidade eletrosmótica, $v_{\mathrm{eo}}$.

$\mathrm{v}_{t o t}=\mathrm{v}_{e p}+\mathrm{v}_{e o}$

Esta quantidade pode ser medida experimentalmente dividindo-se o comprimento efetivo do capilar pelo tempo de migração $\left(L_{\mathrm{ef}} / t_{\mathrm{m}}\right)$

Notas: 1. Dependendo dos sinais e magnitudes relativas destas velocidades, a velocidade total de um analito pode possuir o mesmo sentido da velocidade eletrosmótica ou o sentido contrário. 2. A velocidade total é a velocidade do íon medida como o seu deslocamento em relação à parede do capilar dividida pelo tempo. 3. O termo "velocidade aparente" também denomina a velocidade total do analito.

\section{Tempo de Migração das Micelas, $t_{\mathrm{mc}}$}

É determinado experimentalmente pelo tempo de migração de um composto que é completamente retido na fase micelar.

\section{RAZÃO DE DISTRIBUIÇÃO DE MASSAS (EM} CROMATOGRAFIA ELETROCINÉTICA MICELAR), $\boldsymbol{k}_{\text {MEKC }}$

$$
\text { É definida como: }
$$

$$
k_{M E K C}=\frac{n_{m c}}{n_{a q}}=K \cdot \frac{V_{m c}}{V_{a q}}
$$

onde $n_{\mathrm{mc}}$ e $n_{\text {aq }}$ são os números de moles de analito nas fases micelar e aquosa, respectivamente, $K$ é a constante de distribuição e $V_{\mathrm{mc}}$ e $V_{\text {aq }}$ são os volumes correspondentes das fases.

Notas: 1. Para o caso de analitos eletricamente neutros, $k_{\mathrm{MEKC}}$ pode ser diretamente calculado a partir dos tempos de migração:

$$
k_{M E K C}=\frac{\left(t_{m}-t_{e o}\right)}{t_{e o}\left(1-\frac{t_{m}}{t_{m c}}\right)}
$$

2. $k_{M E K C}$ não deve ser confundido com o fator de retenção $\mathrm{k}$ (em cromatografia de coluna). Entretanto, é análogo à razão de distribuição de massas (em cromatografia).

\section{RAZÃO DE DISTRIBUIÇÃO DE MASSAS (EM CROMATOGRAFIA ELETROCINÉTICA EM MICROEMULSÃO), $\boldsymbol{k}_{\text {MEEKC }}$}

Definido de forma análoga à razão de distribuição de massas em MEKC, $k_{\text {MEKC }}$, substituindo-se os termos para as micelas pelos termos correspondentes para a microemulsão.

\section{LISTA DE ACRÔNIMOS}

ACE Eletroforese Capilar de Afinidade

CAE Eletroforese Capilar de Afinidade

CE Eletroforese Capilar

CEC Eletrocromatografia Capilar

CGE Eletroforese Capilar em Gel

CIEF Focalização Isoelétrica Capilar

CITP Isotacoforese Capilar

CZE Eletroforese Capilar de Zona

CSE Eletroforese Capilar de Peneiramento

EKC Cromatografia Eletrocinética

MECC Cromatografia Capilar Eletrocinética Micelar

MEECC Cromatografia Capilar Eletrocinética em Microemulsão

MEEKC Cromatografia Eletrocinética em Microemulsão

MEKC Cromatografia Eletrocinética Micelar

\section{SÍMBOLOS}

e Carga elementar

$\boldsymbol{E} \quad$ Campo elétrico

$f \quad$ Coeficiente de atrito

$K \quad$ Constante de distribuição

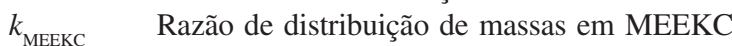

$k_{\mathrm{MEKC}}$ Razão de distribuição de massas em MEKC

$L_{\text {ef }} \quad$ Comprimento efetivo do capilar

$L_{\text {tot }} \quad$ Comprimento total do capilar

$n_{\text {aq }} \quad$ Número de moles de analito na fase aquosa

$n \quad$ Número de moles de analito na fase micelar

$r \quad$ Raio de Stokes

$t_{\mathrm{eo}} \quad$ Tempo de migração eletrosmótica

$t_{\mathrm{m}} \quad$ Tempo de migração do analito

$t_{m c} \quad$ Tempo de migração das micelas

$V_{\text {aq }} \quad$ Volume da fase aquosa

$V_{\mathrm{mc}}^{\mathrm{aq}} \quad$ Volume da fase micelar

$z$

$\varepsilon_{\mathrm{r}}$

$\varepsilon_{0}$

$\zeta$

$\eta$

$\mu$

$\mu_{\text {ef }}$

Número de cargas elementares

Permitividade da solução

Permitividade do vácuo

Potencial eletrocinético (ou zeta)

Viscosidade dinâmica

Mobilidade eletroforética

Mobilidade efetiva

Mobilidade eletrosmótica

Mobilidade eletroforética

Taxa de migração

Velocidade eletrosmótica 
$v \quad$ Velocidade eletroforética

$v_{\text {tot }} \quad$ Velocidade total do analito

$u \quad$ Mobilidade eletrosmótica

\section{REFERÊNCIAS}

1. Férard, G.; Pure Appl. Chem. 1994, 66, 891.

2. McNaught, A. D.; Wilkinson, A.; Compendium of Chemical Terminology (The Gold Book), $2^{\text {nd }}$ ed., Blackwell Science: Oxford, 1997.

3. Knox, J. H.; J. Chromatogr., A 1994, 680, 3.

4. Ettre, L. E.; Pure Appl. Chem. 1993, 65, 819.

5. Foret, F.; Krivankova, L.; Bocek, P.; Capillary Zone Electrophoresis, VHC, Weinheim, 1993.

6. Engelhardt, H.; Beck, W.; Schmitt, T.; Capillary Electrophoresis. Methods and Potentials, Vieweg: Wiesbaden, 1996.

7. Camillari, P.; Capillary Electrophoresis, $2^{\text {nd }}$ ed., CRC Press: Boca Raton, FL, 1998.
8. Baker, D. E.; Capillary Electrophoresis, John Wiley: New York, 1995.

9. Khaledi, M. G.; High-Performance Capillary Electrophoresis, John Wiley: New York, 1998.

10. Kok, W.; Chromatographia supplement 2000, 51.

11. Deyl, Z.; Svec, F.; Capillary Electrochromatography, Elsevier Science: Amsterdam, 2001

12. Bartle, K.; Myers, P.; Capillary Electrochromatography, Royal Society of Chemistry: Cambridge, 2001.

13. Tavares, M. F. M.; Quim. Nova 1996, 19, 173.

14. Tavares, M. F. M.; Quim. Nova 1997, 20, 493.

15. Colombara, R.; Tavares, M. F. M.; Massaro, S.; Quim. Nova 1997, 20, 512.

16. Jager, A. V.; Tavares, M. F. M.; Quim. Nova 2001, 24, 363.

17. Silva, J. A. F. da; Quim. Nova 2003, 26, 56.

18. Gervasio, A. P. G.; Lavorante, A. F.; Moraes, M. C. B.; Giné, M. F.; Miranda, C. E. S.; Carrilho, E.; Quim. Nova 2003, 26, 65.

19. Miranda, C. E. S.; Carrilho, E.; Gervasio, A. P.; Giné, M. F.; Quim. Nova 2002, 25, 412. 